LIAMES 2 - pp. 29-46, Primavera 2002

\author{
Eduardo Rivail Ribeiro ${ }^{1}$ \\ (Museu Antropológico/UFG - University of Chicago)
}

\title{
O Marcador de Posse Alienável em Karirí: Um Morfema Macro-Jê Revisitado
}

\begin{abstract}
:
This paper is a result of an ongoing project of lexical compilation and grammatical analysis of Karirí (also known as Kirirí), an extinct indigenous language from Northeast Brazil. Although two of its dialects are known only through short wordlists (Martius 1867), two of them were fairly welldocumented-Kipeá (Mamiani 1877, 1942), on which this paper is based, and Dzubukuá (Nantes 1896). Karirí has been included in the Macro-Jê stock (Rodrigues 1986, 1999), although in rather hypothetical terms. However, in spite of the lack of comprehensive lexical comparison to date, recent studies have shown very suggestive cases of grammatical affinities between Karirí and other Macro-Jê languages. One of them, first mentioned by Rodrigues (1992a: 386), is the existence, in Jê, Maxakalí, Boróro, and Karirí, of an apparently cognate morpheme marking alienable possession, although the evidence for the existence of this morpheme in Karirí provided then was quite cursory. The main purpose of the present work is to provide further support for the existence of the marker of alienable possession in Karirí. In addition, this paper briefly discusses the syntactic nature of genitive constructions containing such a morpheme and the existence, in the Jê family, of another morpheme of similar functions, probably reconstructible for Proto-Jê and cognate with a Tupí-Guaraní prefix.
\end{abstract}

\section{INTRODUÇÃO}

Karirí (ou Kirirí) é uma língua extinta outrora falada no nordeste brasileiro. Ainda que dois de seus dialetos, o Pedra Branca e o Sabujá (Martius 1867), sejam conhecidos apenas por intermédio de listas vocabulares curtas, dois deles foram razoavelmente bem documentados por missionários católicos no período colonial — o Kipeá (Mamiani

${ }^{1}$ Estudante de doutorado na Universidade de Chicago e pesquisador da Seção de Etnolingüística do Museu Antropológico da Universidade Federal de Goiás. Este trabalho é parte de um projeto mais amplo de documentação e análise da língua Karirí, cujo principal objetivo, em curto prazo, é a elaboração de um dicionário baseado na coleta de todo o material lexical disponível nas obras dos missionários Luiz Vincêncio Mamiani (dialeto Kipeá) e Bernardo de Nantes (dialeto Dzubukuá). Eu gostaria de agradecer ao CNPq (Processo 200018/98-1), à Fundação Wenner-Gren para Estudos Antropológicos e à Universidade de Chicago, por apoiarem financeiramente meus estudos de doutorado, e à lingüista Luciana Dourado (Universidade de Brasília), por fornecer detalhes a respeito da morfologia do Panará. Críticas, sugestões e comentários serão muito bem vindos. Endereço eletrônico: erribeir@midway.uchicago.edu 
1877[1699], 1942[1698]), no qual o presente estudo se baseia, e o Dzubukuá (Nantes 1896 [1709]). A língua era ainda falada pelo menos até a primeira metade do século passado, havendo hoje em dia mais de quatro mil indivíduos que se identificam etnicamente como Karirí (ou Kirirí, incluindo Karirí-Xokó e Xukurú-Karirî), ${ }^{2}$ que são, no entanto, monolíngües em português, ainda que alguns deles se lembrassem até bem recentemente de palavras isoladas de seu idioma original (Bandeira 1972, Meader 1978).

Apesar da inexistência, até o momento, de comparações lexicais aprofundadas, estudos recentes têm revelado casos muito interessantes de afinidades gramaticais entre o Karirí e línguas do tronco Macro-Jê (Rodrigues 1992, 1992a, 1999, 2000). Um deles seria a existência, em Jê do Norte, Boróro, Maxakalí e Karirí, de um morfema provavelmente cognato usado para tornar certos nomes possuíveis, chamado 'marcador de posse alienável' por Rodrigues (1992a). As evidências apresentadas então para o Karirí, no entanto, tinham um caráter um tanto especulativo. O presente estudo tem por propósito apresentar evidências adicionais que confirmam a existência deste morfema em Karirí, com base na excelente descrição do dialeto Kipeá que nos foi legada por Mamiani (1877) e em dados extraídos de seu Catecismo (1942). Além disso, descreve-se a existência de um outro morfema alienador nas línguas jê, provavelmente reconstruível para o Proto-Jê e cognato com um morfema de função idêntica em Tupí-Guaraní.

\section{UMMARCADOR MACRO-JÊ DE POSSEALIENÁVEL}

Como mencionamos acima, uma das poucas evidências para o parentesco genético entre o Karirí e outras línguas do tronco Macro-Jê, apontada por Rodrigues (1992a: 386, 1999: 190-192), é a existência, em Jê do Norte, Maxakalí, Boróro e Karirí, de um morfema aparentemente cognato usado para marcar posse alienável. Nestas línguas, certos nomes não podem ser possuídos diretamente, requerendo a 'intermediação' de um nome obrigatoriamente possuído - na maioria dos casos, um nome genérico traduzível como 'coisa'. Os prováveis cognatos são õ, nas línguas jê do Norte (Panará, Apinajé, Kayapó, Timbira, etc.), yõy ?õy ?õ em Maxakalí, o em Boróro e $u$ - em Karirí. O uso deste morfema é ilustrado pelos exemplos abaixo, das línguas panará e parkatêjê (ambas do subgrupo jê do Norte) e boróro: ${ }^{3}$

\footnotetext{
${ }^{2}$ Dados do Instituto Socioambiental (2000: 535-538).

3 Abreviações: ANTI 'marcador de antipassiva', Clas 'morfema classificatório', com 'adposição comitativa', COR 'co-referencial', DAT 'adposição dativa', ENF 'morfema enfático', ERG 'adposição ergativa', IMP 'imperfectivo', INSTR 'adposição instrumental', LOC 'adposição locativa', PASs 'passado', PL 'plural', pos 'morfema possessivo ('alienador')', REL 'prefixo relacional', RELAT 'relativizador'. Os dados do Karirí no presente trabalho preservam a transcrição de Mamiani e Nantes (exceto na marcação do acento, suprimida aqui). Para detalhes sobre a fonologia do Kipeá, ver Azevedo (1965). A tradução dos morfemas gramaticais do Karirí (especialmente no caso dos marcadores de tempo e aspecto) ainda tem caráter preliminar.
} 
Ribeiro: O Marcador de Posse Alienável em Karirí: Um Morfema...

Panará (Dourado 2002: 97)

(1)

a.

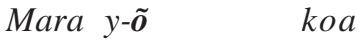

$$
\begin{aligned}
& \text { ele REL-posse casa } \\
& \text { 'casa dele' }
\end{aligned}
$$

Parkatêjê (Ferreira 2001: 150)

a.

$\begin{array}{ll}\text { Piare j- } \tilde{\boldsymbol{o}} & \text { hêti } \\ \text { Piare REL-coisa } & \text { aranha } \\ \text { 'aranha do Piare' } & \end{array}$

Boróro (Crowell 1977: 178)

(3) $\begin{array}{lll}\text { b. } & s-\tilde{\boldsymbol{o}} & \text { koa } \\ & \text { 3-posse } & \text { casa } \\ \text { 'sua (própria) } & \text { casa' }\end{array}$

$\begin{array}{lll}\text { b. } & h-\tilde{\boldsymbol{o}} & \text { hêti } \\ & \text { 3-coisa } & \text { aranha } \\ & \text { 'aranha dele' } & \end{array}$

$\begin{array}{lll}\text { b. } & \varnothing-o & \text { tori } \\ \text { 3-pos } & \text { pedra } \\ \text { 'pedra dele' } & \end{array}$

Além de ocorrer em construções genitivas como as ilustradas acima, o morfema alienador pode, nas línguas em que ocorre como uma palavra independente, formar um sintagma nominal por si só (4), além de ocorrer em predicados possessivos como (5) abaixo.

Boróro (Crowell 1979:217)

i-n-o kuri-re

1-REL-POS grande-NEUTRO

'A minha [casa] é grande.'

(5)

Panará (Dourado 2001: 73)

$\begin{array}{lll}\text { teseya } & s \text { - } \boldsymbol{o} & \text { puu } \\ \text { Teseya } & \text { 3-posse } & \text { roça' } \\ \text { 'Teseya tem roça.' } & & \end{array}$

\subsection{Aspectos morfológicos}

Além de suas semelhanças fonológicas, semânticas e funcionais, os prováveis cognatos também apresentam propriedades morfológicas comuns nas diferentes línguas. Assim, em algumas das famílias que se têm afiliado ao tronco Macro-Jê — a saber, Jê, Boróro, Ofaié, Karirí e Karajá —, a maioria dos temas verbais, nominais e (em alguns casos) adposicionais dividem-se em duas classes lexicais, com base em diferenças nas séries de prefixos pessoais com que ocorrem. A principal diferença diz respeito à ocorrência de um 'prefixo de ligação' com itens de uma das classes (tradicionalmente chamado 'prefixo relacional'; Rodrigues 1953, 1992, 2000; Ribeiro 2002, 2002a), além da ocorrência, com itens de uma e outra classe, de alomorfes diferentes para o prefixo de terceira pessoa. ${ }^{4}$ Tais diferenças são ilustradas abaixo com exemplos de ambas as classes em Panará e Boróro:

${ }^{4}$ Minha análise dos relacionais difere da de Rodrigues (1992, 1999, 2000) em alguns aspectos, o principal deles sendo que Rodrigues também considera como relacionais (mais precisamente, 'relacionais de não-contigüidade') prefixos que eu traduzo simplesmente como marcadores de terceira pessoa, como 
(6)

(7)

a.
Soti
animal REL-boca
'boca do animal'

Boróro (Crowell 1983: 92, Crowell 1977: 167)

a.

$$
\begin{aligned}
& i \text {-tuie } \\
& \text { 1-irmã mais velha } \\
& \text { 'minha irmã mais velha' }
\end{aligned}
$$

$$
\begin{aligned}
& i-n-o g w a \\
& \text { 1-REL-boca } \\
& \text { 'minha boca' }
\end{aligned}
$$

b. $\quad I-t \varepsilon$

3-perna

'perna dele'

b. s-akoa

3-boca

'boca dele' b. u-tuie

3-irmã mais velha

'sua irmã mais velha'

b. $\quad \begin{aligned} & \text {-ogwa } \\ & \text { 3-boca } \\ & \text { 'sua boca' }\end{aligned}$

Note-se que os marcadores de posse alienável tanto em Jê quanto em Boróro (e, muito provavelmente, também em Karirí; ver Seção 3.2 abaixo) pertencem à classe de raízes que recebem prefixos relacionais, como ilustrado pelos exemplos acima.

\subsection{Gramaticalização: de nome a prefixo}

Como veremos, cognatos dos morfemas alienadores em Karirí e Tupinambá são prefixos e, como tais, não ocorrem independentemente. Nas famílias jê e boróro, por outro lado, as traduções dadas ao marcador de posse alienável nas fontes originais variam do mais concreto ao mais abstrato, do mais lexical ('coisa', em Parkatêjê) ao mais gramatical ('prefixo de possessão alienável', em Xavánte), mas não está claro se tais diferenças em tradução se referem a diferentes graus de gramaticalização (Tabela 1). Em todas as línguas em que o marcador de posse alienável ocorre como uma palavra independente, seu comportamento morfológico parece ser idêntico ao de outros nomes possuídos. Mesmo nos casos em que o morfema alienador é traduzido como 'pronome' (Apinajé, Boróro), 'partícula' (Xerénte) ou mesmo 'prefixo' (Xavánte), não se apresentam evidências gramaticais que permitam distingui-lo de outros nomes possuídos.

s- no Panará e no Kipeá. Na análise que proponho, apenas os 'marcadores de contigüidade' (como os prefixos $j$ - do Panará, $n$ - do Boróro e $d z-/ y$ - do Karirí) são prefixos relacionais propriamente ditos (ver Ribeiro 2002, 2002b). Sigo, assim, a análise que Rodrigues (1953) antes fizera do Tupinambá, dividindo as raízes desta língua em duas classes de temas, a classe I, cujos temas não recebem prefixo de relação, e a classe II, cujos temas recebem prefixo de relação. Como nas línguas macro-jê aqui discutidas (bem como em outras línguas do tronco Tupí e da família karib; Rodrigues 1992), "à classe I pertencem todos os temas começados por consoante ou semivogal e parte dos temas começados por vogal; à classe in pertencem só temas começados por vogal" (Rodrigues 1953: 123). Neste trabalho, Rodrigues dá o nome de "prefixo de relação' exclusivamente ao 'marcador de contigüidade' $r$-, que ocorre com os temas da classe II quando estes "são imediatamente precedidos por um substantivo (salvo em caso de composição) ou pelos pronomes das 1a. e 2a. pessoas [...]: kunumi r-úb-a 'o pai do menino', xe-r-úb 'eu tenho pai'." Esta é, aliás, a abordagem que preservo em minha análise da morfologia do Karajá (1996). 
Tabela 1. Famílias Jê e Boróro: traduções dadas aos cognatos do 'marcador de posse alienável'

\begin{tabular}{|l|l|l|}
\hline Língua & \multicolumn{1}{|c|}{ Fonte } & \multicolumn{1}{c|}{ Tradução do morfema } \\
\hline Apinajé & Ham, Waller \& Koopman 1979: 2 & 'pronomes possessivos', 'palavras possessivas' \\
\hline Panará & Dourado 2002: 97 & 'posse, propriedade (nome)' \\
\hline Canela-Krahó & Popjes \& Popjes 1986: 169 & 'possession marker' \\
\hline Parkatêjê & Ferreira 2001: 150 & 'coisa (nome)' \\
\hline Xikrín & Costa 2002: 82 & 'posse, propriedade (nome)' \\
\hline Xavante & McLeod \& Mitchell 1980: 88-90 & 'possessão alienável (prefixo)' \\
\hline Xerénte & Krieger \& Krieger 1994: 27, 43 & 'posse (partícula)' \\
\hline Kaingáng & Wiesemann 1981:154 & 'coisa de alguém (nome)' \\
\hline Boróro & Crowell 1979: 214-218 & 'alienable possession (pronome)' \\
\hline
\end{tabular}

\subsection{Um 'aplicativo nominal'}

O termo 'marcador de posse alienável' requer explicação. Ao contrário do que esta terminologia pode sugerir, tais morfemas não ocorrem apenas com nomes alienáveis e, por outro lado, vários nomes alienáveis podem ser possuídos diretamente, de maneira semelhante a nomes obrigatoriamente possuídos. Em vez de indicar a alienabilidade de certos itens lexicais, a principal função deste morfema nas diferentes línguas em que ocorre é assinalar mudanças nas relações gramaticais entre um nome e seus argumentos, de maneira análoga a mecanismos que alteram a valência original de um verbo (aplicativos e morfemas causativos, por exemplo). ${ }^{5} \mathrm{Ou}$ seja, tais morfemas desempenham a função de alienadores, possibilitando a ocorrência do nome com um argumento a mais (neste caso, um possuidor) ou um argumento diferente de seu argumento original, tomando-se 'alienar em seu sentido tradicional de "transferir para outrem o domínio de; tornar alheio; alhear". Como 'aplicativos nominais', são usados tanto para tornar possuíveis nomes que, de outra maneira, não podem ocorrer com um possuidor, quanto para alterar a natureza das relações entre itens possuíveis e seus possuidores. Isto explica sua ocorrência com (i) nomes que não podem ser diretamente possuídos, (ii) nomes que são opcionalmente possuíveis ou (iii) nomes que são obrigatoriamente possuídos.

${ }^{5}$ As semelhanças entre morfemas alienadores e morfemas verbais que alteram relações gramaticais são ainda mais evidentes em línguas como o Karirí, onde um provável cognato do marcador de posse alienável ocorre com raízes verbais, desempenhando funções antipassivas (ver Ribeiro 2002b). Em Karirí, uma língua ergativa (Larsen 1984), construções relativas que se referem ao argumento absolutivo de um verbo são criadas pelo acréscimo do prefixo de 3 a. pessoa co-referencial $d i$ - e o sufixo 'relativizador' $r i$ ao tema verbal (a). Além disso, construções relativas referindo-se ao argumento ergativo podem ser criadas pelo acréscimo, ao tema verbal, do prefixo $u$-, provavelmente cognato do marcador de posse alienável nesta língua (b):

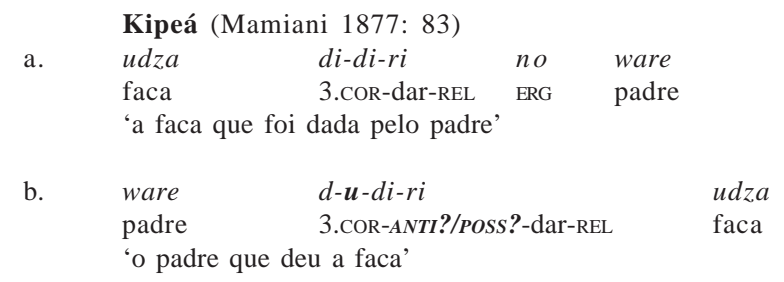


Em várias das línguas macro-jê para as quais há descrições gramaticais disponíveis, certos nomes são descritos como sendo 'impossuíveis'. Em Panará, por exemplo, esta classe incluiria nomes referentes a "elementos da natureza (terra, montanha, árvore, céu, rios, cachoeira, etc.) e nomes próprios" (Dourado 2001: 67), o mesmo se dando em Parkatêjê (Ferreira 2001:149-150). Contudo, como demonstrado por Dourado, em Panará alguns destes nomes podem de fato ser possuídos por intermédio do marcador de posse alienável $\tilde{o}$ :

Panará (2001: 67,77)

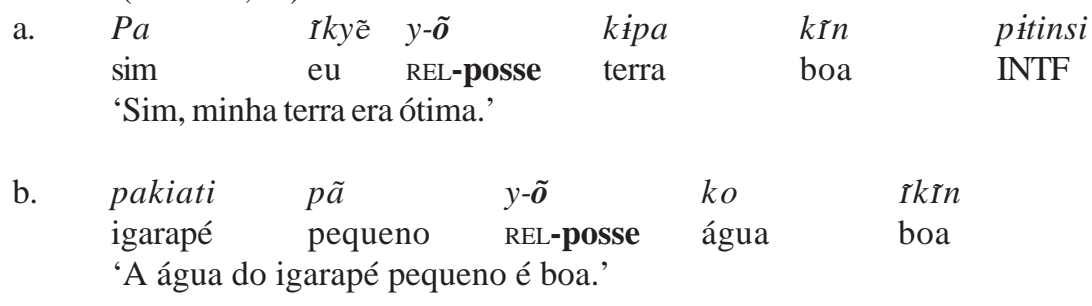

Em Apinajé, de acordo com Ham, Waller \& Koopman (1979: 15), nomes de "pertences feitos pela própria pessoa" comportam-se de maneira análoga a nomes de partes do corpo, sendo possuídos diretamente. ${ }^{6} \mathrm{O}$ morfema alienador pode, então, ser usado para indicar uma relação não inerente entre o possuidor e a coisa possuída — ou seja, uma relação de posse secundária. Um bom exemplo é a raiz kavs 'cesta', que é alienavelmente possuível e, como tal, pode ocorrer livre, sem possuidor algum (11a), possuída diretamente (11b) ou com a intermediação do morfema alienador $\tilde{o}$ (11c). A escolha entre posse direta e posse 'intermediada' estabelece, assim, uma distinção entre posse inerente, por um lado, e propriedade, por outro. ${ }^{7}$

Apinajé (Ham 1961: 25; Ham, Waller \& Koopman 1979: 2)

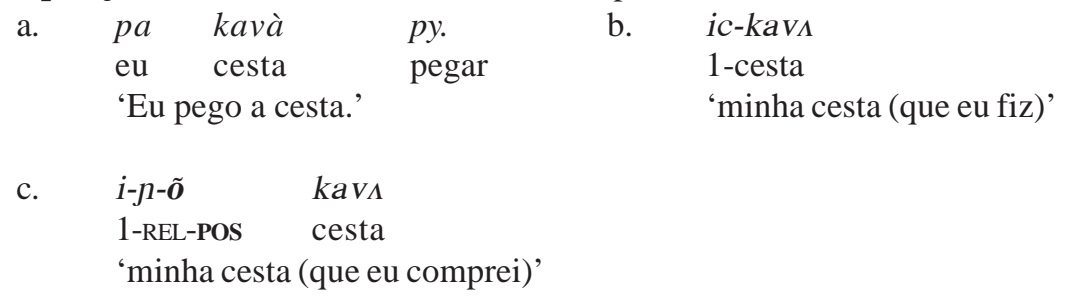

${ }^{6}$ Ver também Ham (1961: 25): "If the word refers to an object which was made by the speaker, to $\operatorname{him}_{7}$ it is inalienable, but to another person it is alienable."

7 Esta distinção é semelhante ao caso do Navajo, mencionado por Nichols:

"In Navajo [...], dependent [i.e. bound] nouns, when owned by someone other than the inalienable possessor, take what is called secondary possession: there are two possessive prefixes, the first indexing the owner and the second marking unspecified possession:

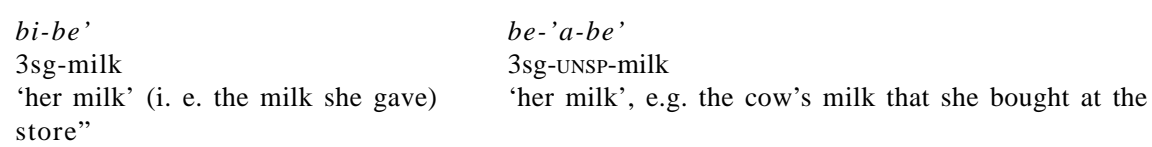

[Nichols 1988: 565] 
Os exemplos do Apinajé acima, em que o morfema alienador indica o caráter não inerente da posse, fornecem pistas para entendermos o uso, em algumas línguas, do marcador de posse alienável com nomes obrigatoriamente possuídos. Como veremos (Seção 3), em Karirí e Panará as raízes para ‘fogo’, em suas formas de citação, vêm sempre precedidas de um morfema que corresponde muito provavelmente ao prefixo de terceira pessoa. Isto sugere que este nome seja originalmente uma raiz obrigatoriamente possuída. O possuidor primário, representado pelo prefixo $i$-, refere-se talvez ao combustível do fogo ('fogo de lenha', etc.). O morfema alienador é usado quando a introdução de um possuidor secundário se faz necessária.

É interessante notar que muitos nomes que requerem o marcador de posse alienável em algumas línguas macro-jê podem ser diretamente possuídos em outras. Assim, 'faca' e 'roça', por exemplo, requerem o uso do marcador de posse alienável em Timbíra e outras línguas jê, mas não em Karirí: Timbira kapi j-õ pur 'roça do Capi', $h$-õ waps 'sua faca' (Rodrigues 1999: 190-191); Karirí cu-bechien 'nossa roça', dz-udza 'minha faca' (Mamiani 1942: 108; 1877: 100). Por outro lado, enquanto 'dinheiro' requer o marcador de posse alienável em Karirí e Xerente, o mesmo não ocorre em Apinajé: a-kàxpore 'teu dinheiro' (Ham, Waller \& Koopman 1979: 15). Isto sugere que o comportamento de uma dada raiz é determinado, antes de tudo, pelo léxico, e não por fatores exclusivamente semânticos. Ainda que generalizações semânticas sejam úteis para o aprendiz da língua, 'alienabilidade' é antes de tudo uma característica determinada pelo léxico. Como sugerido por Nichols (1988: 568-576), nenhuma explicação semântica nos permitiria prever se um determinado nome se comportaria como alienável ou inalienável:

\begin{abstract}
"[...] membership in the 'inalienable' class cannot be predicted from the semantics of the possessive relation, since there are lexical exceptions. A description of the semantics of possession is therefore very possibly not even part of the grammar of a language; it is part of the linguist's personal understanding of particular grammatical features, or the native speaker's personal and conscious reflection on language. 'Alienability', then, is basically not a semantic matter. Of all grammatical phenomena it is the most like valence in that some nouns require particular kinds of dependents (bound nouns require possessors) and some nouns dictate the form to be taken by their dependents [...]. Like valence, it lends itself to semantic generalizations over the lexical membership of form classes, but is not a piece of meaning that the speaker chooses to communicate." [Nichols 1988: 575-576]
\end{abstract}

\title{
3. REVISITANDO O MARCADOR DE POSSEALIENÁVELEM KARIRÍ
}

As evidências apontadas por Rodrigues para a existência do marcador de posse alienável em Karirí são, no entanto, muito menos óbvias que aquelas existentes para as demais línguas. Em Kipeá, Mamiani descreve doze classificadores possessivos — mais precisamente, lexemas de sentido genérico que ocorrem em construções genitivas tais

\footnotetext{
${ }^{8}$ Além de seu uso em construções 'classificatórias' como as ilustradas em (12), tais morfemas podem também ocorrer por si sós (Mamiani 1942: 107):

$\begin{array}{lllllllll}\text { no } & \text { si-di-cri-bae } & \text { vdje } & \text { boho, } & \text { uneca } & \text { boho } & \text { no } & \text { Tupa } & \text { cu-do-ho. } \\ \text { pois } & \text { 3-dar-PASS-IMP } & \text { legumes } & \text { ou } & \text { criação } & \text { ou } & \text { ERG } & \text { Deus } & \text { 2PL-DAT-ENF }\end{array}$

'Pois Deus nos dá tudo, sejam frutos da roça, ou da criação.'
} 
como (12) abaixo (Mamiani 1877: 59-61; Rodrigues 1997). ${ }^{8}$ Baseando-se no fato de que dez destes classificadores começam por $u$-, Rodrigues (1992a) sugere que esta vogal seria um prefixo fossilizado, cognato com o marcador de posse alienável nas línguas jê, no Maxakalí e no Boróro, "ao qual se acrescentaram outros morfemas mais específicos". O uso destes classificadores é ilustrado pelos exemplos abaixo:
a.

dz-upodo do sabuca
1-assado INSTR galinha
'minha galinha assada'
b. dz-uba do sabuca 1-presente INSTR galinha 'minha galinha (de presente)'

Tabela 2. Classificadores possessivos em Kipeá-Karirí (Mamiani 1877: 59-61; Rodrigues 1997: 72-74)

\begin{tabular}{|l|l|}
\hline enki & 'animais domesticados'9 \\
\hline uapru & 'comida coletada' \\
\hline ude & 'comida cozida' \\
\hline upodo & 'comida assada' \\
\hline udje & 'produtos da roça (exceto mandioca)'10 \\
\hline uanhi & 'mandioca' \\
\hline ubo & 'frutas (colhidas verdes para amadurecer em casa)' \\
\hline uito & 'coisas achadas' \\
\hline uboronunu & 'presas de guerra' \\
\hline$u k i s i$ & 'coisas recebidas em partilha' \\
\hline$u b a ́$ & 'presentes' \\
\hline$e$ & 'coisas carregadas' \\
\hline
\end{tabular}

A hipótese apresentada por Rodrigues ainda aguarda confirmação à luz de evidências lexicais adicionais. No entanto, uma análise mais cuidadosa dos dados do Kipeá apresentados por Mamiani, tanto em seu catecismo quanto em sua gramática, revela que o marcador de posse alienável em Karirí tem uma distribuição muito mais ampla e claramente identificável

${ }^{9}$ Há uma outra palavra para 'animais domesticados', uneca (Mamiani 1942: 107, 145), que, no entanto, não parece ser usada em construções 'classificatórias' como as exemplificadas acima (pelo menos, não com a mesma freqüência de enki).

${ }^{10}$ De fato, como ilustrado pelo exemplo abaixo (Mamiani 1942: 108), muicu 'mandioca' pode também ocorrer com o classificador genérico para 'produtos da roça', udje, um fato não mencionado por Rodrigues (1997):

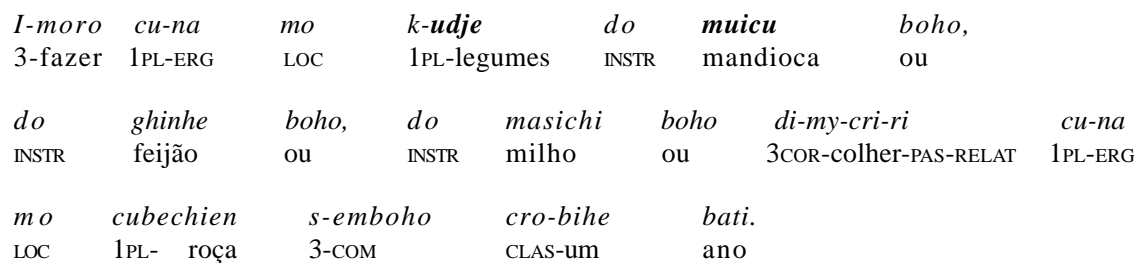

'Do mesmo modo havemos de fazer com os frutos que colhemos em um ano na roça, ou de mandioca, ou de feijões, ou de milho.' 
do que sugerido por Rodrigues. Assim, como descrito por Mamiani (1877: 25), algumas raízes - tais como $s u$ 'fogo' - requerem o uso de um prefixo $u$ - quando se faz necessária a identificação do possuidor:

\begin{abstract}
"A esta [quinta] declinação se reduz o nome Isù, fogo ou lenha, que usando-se ordinariamente pela primeira Declinação, quando se quer declarar o possessor da lenha, se usa por esta quinta Declinação, \& então perde o I natural na composição com os artigos: v. g. Dzusù, minha lenha; Asù, tua lenha; Susù, sua lenha. E do mesmo modo se declina algum nome semelhante, que a praxe ensinará melhor." [Mamiani 1877: 25, grifo nosso; quanto às declinações de Mamiani, ver Seção 3.2 abaixo] ${ }^{11}$
\end{abstract}

O comportamento morfológico desta raiz em Karirí é, assim, extremamente semelhante ao que ocorre em pelo menos uma língua da família Jê, o Panará. Nesta língua, a forma de citação da raiz para 'fogo' é isi (Dourado 2001: 200-202). Este $i$-, contudo, desaparece quando a raiz é precedida por um possuidor. De maneira análoga ao que ocorre em Karirí (14), a raiz para ‘fogo’ em Panará não pode ser possuída diretamente, requerendo o morfema possessivo $\tilde{o}(13)$ :

Panará (Luciana Dourado, comunicação pessoal, 31/3/2002)

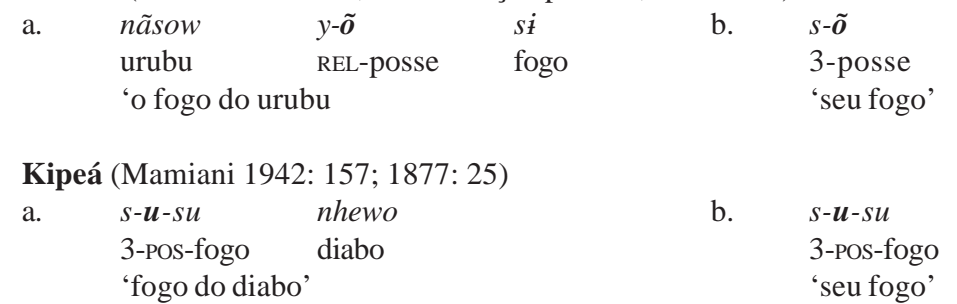

Também ocorrem com o prefixo $u$ - as raízes renghe 'velho' e rute 'velha', quando possuídas, circunstância em que assumem o significado de 'esposo' e 'esposa', respectivamente (em uma maneira que lembra o português, por exemplo, onde, na linguagem familiar, 'meu velho' e 'minha velha' assumem conotações semelhantes): $i$-renghe '(é) velho', i-rute '(é) velha' (Mamiani 1942: 106); s-u-renghe 'seu esposo', s-u-rute 'sua esposa' (Mamiani 1942: 213). Curiosamente, Rodrigues (1948: 201) já havia apontado o papel do formativo $u$ - na diferenciação entre 'velho, velha' e 'esposo, esposa', ${ }^{12}$ mas não o identifica com o marcador de posse alienável em seus trabalhos posteriores sobre este assunto (Rodrigues 1992a, 1997, 1999:192). Como nas demais línguas mencionadas acima, o tema formado com o prefixo $u$ - também ocorre em predicados possessivos (15):
Kipeá (Mamiani 1942: 58)

$\begin{array}{lll}\text { S-u-renghe }=\text { kie } & \text { cune } & \text { Santa Maria? } \\ \text { 3-POS-velho=NEG } & \text { porventura } & \text { Santa Maria } \\ \text { 'Não foi [porventura] casada [lit. teve marido] a Virgem Maria?' }\end{array}$

${ }^{11}$ O mesmo se dá em Dzubukuá: idhu 'fogo', $d z-u$ - $d h u$ 'meu fogo', etc. (Nantes 1896: 301).

12 "Talvez o prefixo u- faça a distinção entre 'esposo' (urenghé) e 'velho' (renghé), 'esposa' (uruté) e 'velha' (ruté).” [Rodrigues 1948: 201]. 
Além disso, o prefixo $u$ - ocorre também com empréstimos tupí-guaraní ao Karirí, tais como tayu 'dinheiro' (13b) e tasi 'enxada', do Tupinambá itajuba e itasyra, respectivamente (Barbosa 1970: 81, 91; Mamiani 1877: 100). É possível que a vogal inicial dos originais tupinambá (que era parte da raiz itá 'pedra, metal') tenha sido reanalisada como um prefixo de terceira pessoa e, então, suprimida, por analogia com itens como isu 'fogo' ${ }^{13} \mathrm{O}$ fato de que o prefixo $u$ - ocorre também com empréstimos sugere que este prefixo ainda seria produtivo no tempo em que a língua foi documentada, uma vez que tais empréstimos dizem respeito a itens introduzidos através do contato com os europeus, sendo, portanto, relativamente recentes. ${ }^{14}$

Kipeá (Mamiani 1877: 100; 1942: 186)

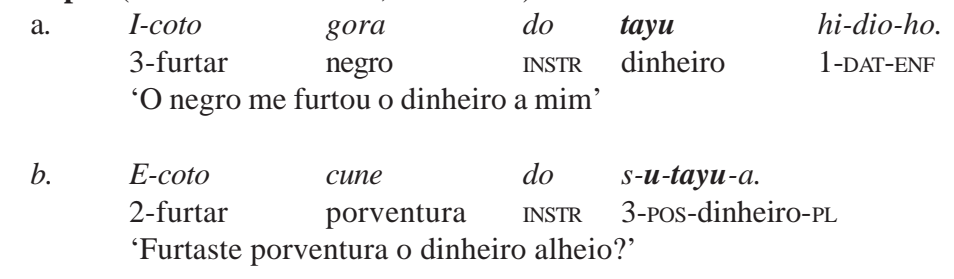

\subsection{A sintaxe dos 'marcadores de posse alienável'}

Nas línguas em que o marcador de posse alienável ocorre como uma palavra independente, como o Boróro e as línguas Jê, este morfema é aparentemente o núcleo do sintagma nominal possessivo, enquanto o nome de significado mais específico é sintaticamente um adjunto. Esta é a análise proposta por Dourado (2001: 70) para o Panará15 e aplicável, provavelmente, às demais línguas Jê e ao Boróro. Da mesma maneira podem ser analisadas as construções envolvendo classificadores possessivos no Karirí (Tabela 1). Nestas construções, é ainda mais evidente o status de adjunto dos nomes de significado específico, uma vez que estes são sempre precedidos da preposição do 'instrumental, alativa, dativa', que forma sintagmas oblíquos e também precede apostos. Assim, construções 'classificatórias' tais como (12a, b) acima e (17) abaixo são sintaticamente análogas a outras construções em que sintagmas nominais são modificados por sintagmas adposicionais adjuntos, como ariba do bunha 'prato de barro', inunu do isu 'línguas de fogo' e budenwo do cro 'sepultura de pedra' (Mamiani 1877, 1942: 63, 71).

\footnotetext{
${ }^{13}$ O prefixo $i$ - que ocorre com a raiz para 'fogo' em Karirí e Panará é provavelmente o mesmo que o marcador de terceira pessoa, comumente usado em formas de citação como marcador default de posse, com itens obrigatoriamente possuídos. O mesmo acontece em Karajá, onde certas raízes ocorrem com um prefixo de terceira pessoa cristalizado, sincronicamente inseparável da raiz. Além de não ser separável, este prefixo difere de seu homônimo, o marcador de terceira pessoa $i$-, por desencadear

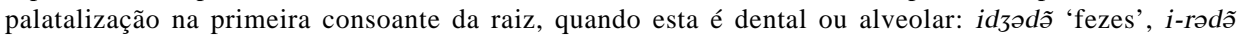
'suas fezes', a-rədə 'tuas fezes', etc.

${ }^{14}$ É provável, ainda, que o prefixo $u$ - '[-animado]' (Mamiani 1877: 56-57) que ocorre com os morfemas djé (u-djé 'o quê?' versus a-djé 'quem?') e tci (u-tci 'aquilo de que não me lembro' versus $a$ - $t c i$ 'aquele de quem não me lembro') seja cognato com o marcador de posse alienável.

"Possuidor e o nome referente a 'posse' formariam um sintagma nominal, cujo núcleo seria este último. O nome referente ao possuído seria um aposto." [Dourado 2001: 70].
} 
Kipeá (Mamiani 1942: 107)

$\begin{array}{lcc}k \text {-enki } & d o & \text { sabuca } \\ \text { 1sG-animal domesticado } & \text { INSTR } & \text { galinha } \\ \text { 'meu animal doméstico, galinha' } & \end{array}$

Como vimos, o marcador de posse alienável em Karirí, por outro lado, liga-se diretamente ao nome possuído, não requerendo o uso da preposição do. Este fato distancia o comportamento sintático deste morfema em Karirí do dos classificadores possessivos em geral, bem como de seus cognatos nas demais línguas macro-jê. O morfema karirí não é um adjunto, mas um afixo gramatical, representando, assim, um grau mais avançado de gramaticalização que os seus cognatos em Jê e Boróro. ${ }^{16}$

\subsection{O prefixo $u$ - e as 'declinações' de Mamiani}

Mamiani (1877) divide as raízes verbais, nominais e adposicionais do Karirí em cinco 'declinações', de acordo com diferenças nas séries de prefixos pessoais com que ocorrem (Tabela 3). Rodrigues (1992, 2000), reanalisando os dados de Mamiani, demonstra que tais declinações apresentam um comportamento que se assemelha muito à situação descrita para línguas como o Panará e o Boróro e divide os lexemas do Karirí em duas classes principais - a exemplo do que ocorre em outras línguas macro-jê, com base na ocorrência de diferentes séries de prefixos pessoais, bem como na ocorrência de prefixos relacionais. Rodrigues sugere que as consoantes $d z$ e y que ocorrem entre o prefixo pessoal e raízes da segunda e da terceira declinações, respectivamente, seriam prefixos relacionais (19a, 20a). Note-se o paralelismo morfológico entre os exemplos abaixo e os exemplos do Panará e do Boróro apresentados acima.

Karirí (Mamiani 1877; a segmentação morfológica segue Rodrigues 1992)

a. $\quad$ hi-padzu
1-pai

$$
\text { 'meu pai' }
$$

a. $\quad h i-d z$-ebaya

1-REL-unha

'minha unha'

a. $\quad h i-(y)-e r a$

1-REL-casa

'minha casa' b. $\quad i$-padzu

3-pai

'pai dele'

b. s-ebaya

3-unha

'sua unha'

b. s-era

3 -casa

'sua casa'

${ }^{16}$ Um levantamento exaustivo dos nomes que ocorrem com o prefixo $u$ - está fora do escopo do presente artigo, devendo ser adiado para quando disponhamos de uma compilação abrangente do léxico karirí. 
Tabela 3. Declinações de Mamiani (1877); a segmentação morfológica segue Rodrigues (1992)

\begin{tabular}{|c|c|c|c|c|c|}
\hline $\begin{array}{l}\text { Pesso } \\
\text { a }\end{array}$ & $\begin{array}{c}1^{\mathrm{a}} \\
\text { declinação }\end{array}$ & $\begin{array}{c}2^{\mathrm{a}} \\
\text { declinação }\end{array}$ & $\begin{array}{c}3^{\mathrm{a}} \\
\text { declinação }\end{array}$ & $\begin{array}{c}4^{\mathrm{a}} \\
\text { declinação }\end{array}$ & $\begin{array}{c}5^{\mathrm{a}} \\
\text { declinação }\end{array}$ \\
\hline & padzu 'pai' & $\begin{array}{l}\text { ambe } \\
\text { 'pagamento' }\end{array}$ & ebaya 'unha' & bate 'morada' & $\begin{array}{l}\text { ubyro } \\
\text { 'barriga' }\end{array}$ \\
\hline $1^{\mathrm{a}}$. & hi-padzu & hi-(y)-ambe & hi-dz-ebaya & hi-bate & dz-ubyro \\
\hline $2^{a}$ & $e-p a d z u$ & $e-y$-ambe & $e-d z-e b a y a$ & $e$-bate & a-byro \\
\hline $3^{\mathrm{a}}$ & $i-p a d z u$ & $s$-ambe & s-ebaya & si-bate & s-ubyro \\
\hline $\begin{array}{l}\text { 1PL. } \\
\text { INCL }\end{array}$ & ku-padzu-a & $\begin{array}{l}\text { k-ambe, } \\
k \text {-ambe-a }\end{array}$ & $k$-ebaya & ku-bate-a & $k$-ubyro-a \\
\hline 3.COR & di-padzu & $d$-ambe & d-ebaya & di-bate & d-ubyro \\
\hline
\end{tabular}

Como vimos acima, o marcador de posse alienável em Jê e Boróro pertence à classe de lexemas que recebem prefixo relacional. O mesmo se dá provavelmente também em Karirí. Nesta língua, nomes formados com o marcador de posse alienável $u$ pertencem à quinta declinação de Mamiani (Tabela 3). Apesar de Rodrigues não incluir exemplos da quinta declinação em sua discussão das classes lexicais do Karirí, é possível considerar esta declinação como uma sub-classe das raízes que recebem prefixos relacionais, com base no fato de que, a exemplo da segunda e terceira declinações, esta classe toma o prefixo $s$ - como marca de terceira pessoa. Além disso, em Dzubukuá encontramos pelo menos um exemplo de uma raiz da quinta declinação ( иса 'querer, amar') ocorrendo com o prefixo hi- na primeira pessoa, seguido pelo prefixo $d z$ - (21). Isto sugere uma hipótese que certamente merece ser investigada: a exemplo do que ocorre na terceira declinação, é possível que o prefixo $d z$ - da quinta declinação tenha sido originalmente um prefixo relacional.

Dzubukuá (Nantes 1896: 307)

$\begin{array}{lllll}\boldsymbol{h i} \text { - } \boldsymbol{d z} \text {-uca } & a \text {-do-a, } & \text { noli } & a \text {-ca-cli } & \text { hi-do-o. } \\ \text { 1-REL?-amar } & \text { 2-DAT-PL } & \text { porque } & \text { 2-amar-PAS } & \text { 1-DAT-ENF } \\ \text { '[Por isso] vos amo, porque vós me amastes' } & \end{array}$

Assim, as evidências apontadas por Rodrigues (1992a) são corroboradas por informações semânticas, morfológicas e, provavelmente, também fonológicas. Apesar de as correspondências fonológicas entre o Karirí e as demais línguas macro-jê serem ainda pouco conhecidas, é interessante mencionar que os poucos casos de prováveis cognatos encontrados até o momento também parecem corroborar a análise do prefixo karirí $u$ - como sendo cognato com o marcador de posse alienável $\tilde{o}$ em Jê: Kipeá $s$ - $\underline{u} \underline{\text { u }}$ 'ele dorme', $d z$ -

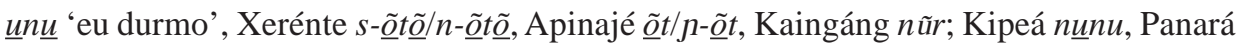
sôt to 'língua', Kaingáng nũnẽ. A correspondência na série para 'dormir' em Karirí e nas várias línguas jê é particularmente reveladora, uma vez que ilustra não apenas uma correspondência exata fonema por fonema, mas também comportamento morfológico análogo nas diferentes línguas. 
Ribeiro: O Marcador de Posse Alienável em Karirí: Um Morfema...

\section{UM OUTRO ‘MARCADOR DE POSSE ALIENÁVEL’ EM JÊ}

Aparentemente, as descrições até agora disponíveis das línguas do sub-grupo Jê Central (Xavánte e Xerénte) não mencionam a ocorrência nestas línguas de um morfema que possa vir a ser cognato do marcador de posse alienável õ das línguas jê do Norte. Contudo, ocorre nestas línguas um morfema que é provavelmente cognato com um outro marcador de posse alienável existente, por exemplo, em Panará. Trata-se, em Xerénte, do morfema $n$-Ĩ $m / s$ - I $m$ (Krieger \& Krieger 1994: 27, 43) e, em Xavánte, do morfema $n h$-im/tsim (McLeod \& Mitchell 1980: 88-90). Tanto em Panará, ${ }^{17}$ quanto em Jê Central, este morfema pertence à classe lexical que apresenta prefixos relacionais. Comparem-se as formas em Panará (22) e Xerénte (23) abaixo:

Panará (Dourado 2002: 98)

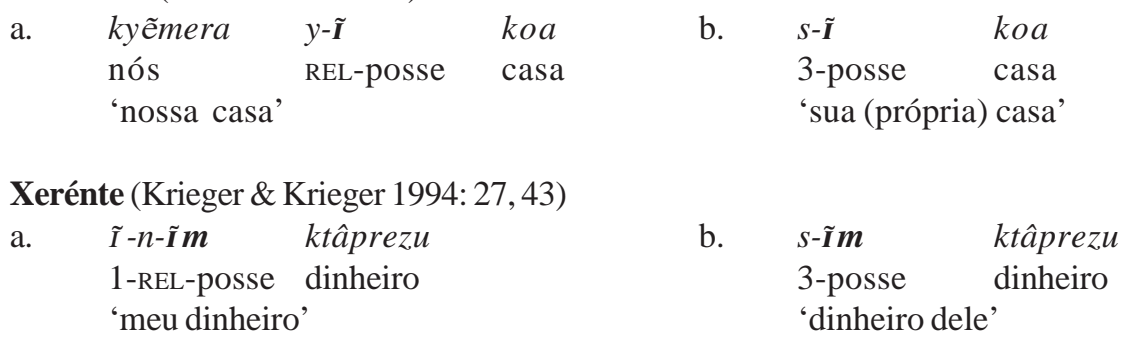

Assim, os dados do Panará e das línguas Jê centrais sugerem que deve ter havido em Proto-Jê pelo menos dois marcadores de posse alienável, cujas diferenças semânticas (além da sua possível ocorrência em outras famílias do tronco Macro-Jê) merecem ser investigadas.

\subsection{Mais um caso de afinidade gramatical entre Jê e Tupí}

Este morfema - - $\tilde{I}$ no Panará, - Ĩ $m$ no Xerénte, -im no Xavánte - encontra um provável cognato também em Tupí-Guaraní. Em Tupinambá, o provável cognato é o prefixo $e-$, que, a exemplo do que ocorre nas línguas Jê, forma temas da classe que recebe prefixos relacionais. Entre os nomes que requerem este prefixo quando possuídos estão vários termos referentes a itens da cultura material, como kuîa 'cuia', mbetara 'tembetá', panaki 'tipo de cesto', nhaẽ 'prato', e pelo menos um termo referente a parte do corpo, tymã 'perna' (Barbosa 1956: 110). Além disso, requerem este prefixo, quando possuídos, todos os nomes deverbais derivados com o prefixo mi- (24).

Tupinambá (Barbosa 1956: 110, 297)
a. xe r-e-mi-ngaú
1 REL-POS-NOM-fazer papas
'meu mingau'

$\begin{array}{lll}\text { b. } & \text { nde } & r-\boldsymbol{e} \text {-mi-mồia } \\ & \mathrm{tu} & \text { REL-POS-NOM-cozer }\end{array}$

'teu cozido'

\footnotetext{
${ }^{17}$ De acordo com Dourado (2001: 72), o morfema possessivo - $\tilde{I}$ do Panará "é pouco produtivo, tendo sido encontrado quase que exclusivamente no discurso dos mais velhos."
} 
Rodrigues (2000a) já havia apontado o nominalizador tupinambá -(e-)mi- como sendo provavelmente cognato com um elemento de função análoga em Xavánte, o morfema ts-imi- nh-imi 'ação realizada por' (McLeod \& Mitchell 1980: 95-97). O cognato deste morfema em Xerénte é $n-m \tilde{I} / s-m \tilde{I}(<* n-) m \tilde{I} / * s-\tilde{I} m \tilde{I})$ : $\tilde{I}-n-m \tilde{I}$ kuI kre 'a minha escrita' (Krieger \& Krieger 1994: 28). Além de suas semelhanças fonológicas e funcionais, os prováveis cognatos em ambas as línguas também compartilham propriedades morfológicas, pertencendo à classe de morfemas que levam prefixos relacionais:

"[...] en una lengua de la familia Jê tenemos un caso no solamente paralelo, sino que con un prefijo probablemente cognado de aquel del Tupí-Guaraní. Se trata de la lengua Xavánte, en la cual hay la nominalización de objeto con el prefijo imi-: $i$ :-ñ-imi-'upté 'la pintura hecha por mí', a-ts-imi-'upté 'la pintura hecha por tî', i-ts-imi-'upté 'la pintura hecha por él' (Hall et al., 1987: 410) (compárese el Tupinambá, de la família Tupí-Guaraní: sjé r-emitym- $a$ 'la(s) cosa(s) plantada(s) por mí', 'mi plantación', né r-emi-tym-a 'la(s) cosa(s) plantada(s) por tí', s-emi-tym-a 'las cosas plantadas por él')." [Rodrigues 2000a: 101]

No entanto, como vimos, a forma do prefixo nominalizador em Tupinambá é $m i-$, não emi-, como sugere Rodrigues (1953: 146, 2000a: 101). A vogal inicial $e$-é, de fato, um prefixo alienador (um 'marcador de posse alienável', na terminologia de Rodrigues), como demonstrado pelo fato de que, na forma absoluta (ou de citação), bem como em compostos, todos os temas descritos acima podem ocorrer sem ela: mi-ngaú 'mingau', itá-nhaẽ 'prato de metal', etc. (Barbosa 1956: 110). Isto torna o paralelismo entre os dados das línguas jê centrais e do Tupinambá ainda mais notável. Assim, em vez de um provável cognato, tem-se provavelmente dois, que interagem de maneira semelhante nas línguas de ambos os grupos. ${ }^{18}$ Mais uma vez, as línguas da família Jê se mostram mais conservadoras que línguas como o Karirí e o Tupinambá. Enquanto em Karirí e Tupinambá os morfemas alienadores tornaram-se prefixos, em Jê ainda mantêm suas propriedades lexicais, preservando não apenas sua independência fonológica, como também (particularmente no caso do alienador $\tilde{o}$ ) seu conteúdo semântico.

\section{COGNATOS EM JÊ DOSUL}

Nas descrições das línguas Jê do Sul (Kaingáng e Xokléng), não há aparentemente menção à ocorrência de marcadores de posse alienável como os encontrados em Jê Central e do Norte. Contudo, prováveis cognatos de ambos os marcadores parecem de fato ocorrer em Jê do Sul, apesar de não desempenharem exatamente as mesmas funções que seus cognatos no resto da família Jê. Em Kaingáng, um provável cognato do morfema õ seria o nome $t i$ ‘coisa de alguém' (Wiesemann 1981:154), enquanto o provável cognato do morfema

${ }^{18}$ Contudo, note-se que não há evidências para a existência de *-mi em Xavánte ou *-m) em Xerénte como morfemas independentes, ao contrário do que ocorre com o prefixo mi- em Tupinambá. Mas é plausível supor que o nominalizador nas línguas Jê centrais tenha sido originalmente um morfema complexo, contendo o morfema alienador. 
I seria o nome $n \varepsilon n$ 'coisa' (Wiesemann 1981:154). ${ }^{19}$ Apesar de não desempenhar a função de 'alienador', o morfema $t i$ ocorre em construções equivalentes a pronomes possessivos (25) e em construções predicativas (26a). Note-se que sua distribuição é idêntica a de outros nomes possuídos, como men 'marido' (26b).

Kaingáng (Wiesemann 1981: 209, 248, 241) ${ }^{20}$

a.

in $=t i$

eu=coisa

'meu'

c. $\quad t i=t i$

ele $=$ coisa

'dele' b. $\quad \tilde{a}=t i$

$\mathrm{tu}=\mathrm{coisa}$

'teu'

d. $\phi i=t i$

ela $=$ coisa

'dela'

Kaingáng (Cavalcante 1987: 26, 18; comunicação pessoal, 3/8/2002)

a.

$i n=t i=w \varepsilon$

$\mathrm{eu}=\mathrm{coisa}=\mathrm{TEMPO} / \mathrm{ASPECTO}$

'Émeu.' b. in $=\boldsymbol{m \varepsilon n}=w \varepsilon$

$\mathrm{eu}=$ marido $=\mathrm{TEMPO} / \mathrm{ASPECTO}$

'É meu marido.'

${ }^{19}$ Note-se que a vogal /i/ do Kaingáng, cuja pronúncia flutua entre [õ] e [i] (Cavalcante 1987: 30, Kindell 1961: 5), corresponde sistematicamente ao /õ/ dos subgrupos Jê do Norte e Jê Central (ver

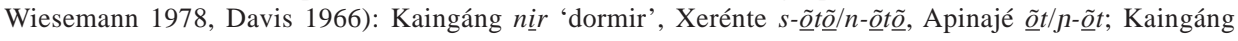
pri 'esposa', Apinajé prõ , Xerénte mrõ 'cônjuge'.

Resta explicar as consoantes iniciais dos morfemas ti e nen em Kaingáng. Como eu sugiro em trabalhos anteriores (Ribeiro 2002, 2002b), apesar de prefixos relacionais serem muito menos produtivos em Kaingáng que nas demais línguas Jê, eles claramente ocorrem em Xokléng, com verbos, posposições e 'descritivos' (Henry 1935: 209; 1948: 202). Em Kaingáng, na grande maioria dos casos, prefixos relacionais e o marcador de terceira pessoa foram reanalisados como parte da raiz. Assim, muitas raízes nesta língua apresentam uma consoante inicial que corresponde, diacronicamente, a um prefixo relacional ( $j$ - ou $n$-) ou a um marcador de terceira pessoa $(\phi$-). Isto se torna evidente quando se comparam dados do Kaingáng com dados de outras línguas Jê em que a flexão relacional é ainda produtiva: $\phi o$ 'pus' (Parkatêjê $h$-ur 'pus dele', mpo t $\int$-ur 'o pus da ferida'), jẽnki 'boca', Xokléng natki (Panará soti j-akoa 'boca do animal', s-akoa 'boca dele'), jã 'queixo' (Apinajé ãm 'queixo', sit $n$-ãm 'o queixo de Sit'), janфe 'ninho' (Xerente sika z-asi 'ninho de galinha', s-asi 'fazer ninho'; Apinajé krâyre j-ae 'ninho de

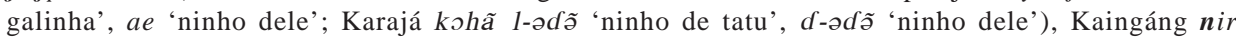
'dormir' (Xerente $n$-õtõ 'dormir', s-õtõ 'ele dorme'), etc.

Portanto, é provável que a primeira consoante em nen 'coisa' corresponda diacronicamente a um prefixo relacional, a exemplo do que ocorre nos dados do Panará (19) e Xerente (20) acima. Considerando-se que o marcador de posse alienável ó pertence à classe lexical que ocorre com prefixos relacionais, seria de se esperar que seu cognato em Kaingáng começasse também com reflexos do prefixo relacional ou do marcador de terceira pessoa. No entanto, há pelo menos um par de exemplos que sugere um processo morfofonêmico que deve ter afetado este morfema em Kaingáng, explicando talvez a sua forma. A raiz para 'bravo, valente' é $j i$, com uma consoante inicial que corresponde à consoante do prefixo relacional, mas que muda para /t/ quando precedida pelo morfema $\phi$ e 'peito (?)' na construção $\phi$ e $t i$ 'com raiva'. (Wiesemann 1981: 158). É possível, assim, que a forma original do morfema $t i$ 'coisa de alguém' tenha sido *ji, que se tornaria $t i$ quando precedida pelo possuidor, forma que acabou se generalizando.

${ }^{20}$ Nestes exemplos, Wiesemann separa os pronomes do nome $t i$ por meio de um hífen ( $\tilde{a}-t i$ 'teu', etc.), que, segundo ela (Wiesemann 1981: 265), é empregado "nas locuções usadas qual nomes". Apesar de exemplos como estes merecerem entradas separadas no Dicionário, não está claro se há diferenças morfológicas entre estas construções e outras do tipo [PRONOME-NOME $]_{\mathrm{SN}}$. 


\section{CONSIDERAÇÕES FINAIS}

Baseado em uma reanálise dos dados do Kipeá (suplementada, quando possível, por dados do Dzubukuá), este artigo — o primeiro resultado de um projeto mais amplo de documentação e análise da língua karirí — confirma a existência nesta língua de um prefixo 'alienador' que tem prováveis cognatos em outras línguas macro-jê, como sugerido inicialmente por Aryon Rodrigues (1992a, 1999). Além de fornecer dados adicionais que apóiam a análise pioneira de Rodrigues — reforçando, assim, a hipótese de parentesco genético entre o Karirí e outras línguas do tronco Macro-Jê —, o presente trabalho discute a natureza sintática deste morfema e demonstra a existência de um outro morfema alienador nas línguas Jê (-Ĩ no Panará, -Ĩ $m$ no Xerénte, -im no Xavánte), provavelmente reconstruível para o Proto-Jê e cognato com um morfema de função idêntica em Tupí-Guaraní (Tupinambá e-).

\section{REFERÊNCIAS BIBLIOGRÁFICAS}

AZEVEDO, Gilda Maria Corrêa de. (1965). Língua Kiriri: descrição do dialeto Kipeá. Dissertação de mestrado. Brasília: Universidade de Brasília.

BANDEIRA, Maria de Lourdes. (1972). Os Kariris de Mirandela: Um Grupo Indígena Integrado. Estudos Baianos 6. Salvador: Universidade Federal da Bahia.

BARBOSA, A. Lemos. (1956). Curso de Tupi Antigo. Rio de Janeiro: Livraria São José. .(1970). Pequeno Vocabulário Português-Tupi. Rio de Janeiro: Livraria São José.

BOSWOOD, Joan. (1973). Evidências para a Inclusão do Aripaktsá no Filo Macro-Jê. Arquivo Lingüístico, 171. Brasília: SIL.

CABRAL, Ana Suelly Arruda Câmara \& Rodrigues, Aryon (orgs.). (2001). Estudos sobre Línguas Indígenas I. Belém: UFPA.

.(2002). Atas do I Encontro Internacional do Grupo de Trabalho sobre Línguas Indígenas da ANPOLL, Tomos I e II. Belém: UFPA.

CAVAlCANTE, Marita Pôrto. (1987). Fonologia e morfologia do Kaingáng: o dialeto de São Paulo comparado com o do Paraná. Tese de doutorado. Campinas: Universidade Estadual de Campinas.

COSTA, Lucivaldo Silva da. (2002). Prefixos relacionais no Xikrín. In Cabral \& Rodrigues (2002), Tomo I, 81-85.

CROWELL, Thomas. (1977). The phonology of Boróro verb, postposition and noun paradigms. In Arquivos de Anatomia e Antropologia 2.159-178. Rio de Janeiro: Instituto de Antropologia Prof. Souza Marques.

.(1979). A grammar of Boróro. Tese de Doutorado, Cornell University.

CROWELl, Jan. (1981). Gramática Pedagógica Borôro. Arquivo Lingüístico, 64. Brasília: SIL.

DAVIS, Irvine. (1966). Comparative Jê phonology. Estudos Lingüísticos: Revista Brasileira de Lingüística Teórica e Aplicada, 1:2.10-24.

DOURADO, Luciana Gonçalves. (2001). Aspectos morfossintáticos da língua Panará (Jê). Tese de doutorado. Campinas: Unicamp. .(2002). A expressão da posse em Panará. In Cabral \& Rodrigues (2002), Tomo I, 96-103. 
FERREIRA, Marília. (2001). Aspectos das classes de palavras em Parkatêjê: uma abordagem tipológicofuncional. In Cabral \& Rodrigues (2001), 147-166.

HAM, Patricia. (1961). Apinayé Grammar. Arquivo Lingüístico, 108. Brasília: SIL.

HAM, Patricia, Waller, Helen, \& Koopman, Linda. (1979). Aspectos da Língua Apinayé. Brasília: SIL.

HENRY, Jules. (1935). A Kaingáng text. IJAL, 8.172-218. (1948). The Kaingáng language. IJAL, 14.194-204.

INSTITUTO SOCIOAMBIENTAL. (2000). Povos Indígenas no Brasil 1996/2000. São Paulo.

KINDELL, Gloria. (1961). Fonêmica Kaingáng. Arquivo Lingüístico, 39. Brasília: SIL.

KRIEGER, Wanda Braidotti \& Krieger, Guenther Carlos (organizadores). (1994). Dicionário Escolar Xerénte/Português, Português/Xerénte. Rio de Janeiro: Junta de Missões Nacionais da Convenção Batista.

LARSEN, Thomas. (1984). Case marking and subjecthood in Kipeá Kirirí. BLS 10:189-205.

MCLEOD, Ruth \& MITCHELl, Valerie. (1977). Aspectos da Língua Xavánte. Brasília: SIL.

MAMIANI, Luiz Vincencio. (1877) [1699]. Arte de Grammatica da Lingua Brasilica da Naçam Karirí. 2 ${ }^{\mathrm{a}}$. edição. Rio de Janeiro: Bibliotheca Nacional. .(1942) [1698]. Catecismo da Doutrina Christãa na Lingua Brasilica da Nação Karirí. Lisboa. (Edição facsimilar, Rio de Janeiro: Biblioteca Nacional).

VON MARTIUS, Carl Friedrich. (1867). Beiträge zur Sprachenkunde Amerika's zumal Brasiliens, vol. II: Wörtersammlung brasilianischer Sprachen. Leipzig: Friedrich Fleisher.

MEADER, Robert E. (1978). Índios do Nordeste: Levantamento sobre os Remanescentes Tribais do Nordeste Brasileiro. Brasília: SIL.

NANTES, Bernardo de. (1896) [1709]. Katecismo Indico da Lingua Karirís. Lisboa. (Edição facsimilar publicada por Julio Platzmann, Leipzig).

NICHOLS, Johanna. (1988). On alienable and inalienable possession. In Shipley, William (editor), In Honor of Mary Haas: From the Haas Festival Conference on Native American Linguistics, 557-609. Berlin, New York, Amsterdam: Mouton de Gruyter.

POPJES, Jack \& Popjes, Jo. (1986). Canela-Krahô. In Derbyshire, Desmond \& Pullum, Geoffrey (editores), Handbook of Amazonian Languages, vol. I, 128-199. Berlin: Mouton de Gruyter.

RIBEIRO, Eduardo Rivail. (1996). Morfologia do verbo Karajá. Dissertação de mestrado. Goiânia: Universidade Federal de Goiás.

.(2002). Relational prefixes and the 'Macro-Jê hypothesis.' Trabalho apresentado no $7^{\text {th }}$ Workshop on Structure and Constituency in the Languages of the Americas. University of Alberta at Edmonton, Canada.

.(2002a). On the grammaticalization of an antipassive marker in Karajá and Karirí. Trabalho apresentado no Workshop on American Indian Languages (WAIL 2002). Santa Barbara: University of California.

.(2002b). Prefixos relacionais no tronco Macro-Jê: um estudo histórico-comparativo. Trabalho apresentado no II Encontro Macro-Jê, Campinas, maio de 2002. 
RODRIGUES, Aryon. (1948). Notas sôbre o sistema de parentesco dos índios Kiriri. Revista do Museu Paulista (Nova Série) 2:193-205.

.(1953). Morfologia do verbo Tupi. In Letras 1.121-152. Curitiba.

Línguas Brasileiras: Para o Conhecimento das Línguas Indígenas. São Paulo: Edições Loyola.

.(1992). Grammatical affinities among Tupí, Karíb, and Macro-Jê. Unpublished manuscript. Universidade de Brasília.

.(1992a). Um marcador Macro-Jê de posse alienável. Anais da $44^{a}$ Reunião Anual da SBPC, p. 386. São Paulo: SBPC.

(1997). Nominal classification in Karirí. Opción 22.65-79.

.(1999). Macro-Jê. In Aikhenvald \& Dixon (editors), The Amazonian Languages. Cambridge: Cambridge University Press.

.(2000). Flexão relacional no tronco lingüístico Macro-Jê. Trabalho apresentado na Reunião Anual da ABRALIN/SBPC, julho de 2000, a ser publicado no Boletim da ABRALIN.

.(2000a). 'Ge-Pano-Carib' versus 'Jê-Tupí-Karib': sobre relaciones lingüísticas prehistóricas en Sudamérica. In Miranda. Luis (editor), Actas del I Congreso de Lenguas Indígenas de Sudamérica, Tomo I, 95-104. Lima: Universidad Ricardo Palma.

WIESEMANN, Ursula. (1978). Os dialetos da língua Kaingáng e o Xokléng. Arquivos de Anatomia e Antropologia 3.199-217. Rio de Janeiro: Instituto de Antropologia Prof. Souza Marques. .(1981). Dicionário Kaingáng-Português, Português-Kaingáng, 2a . edição. Brasília: SIL. 